MUSICA THEORICA 201702

SCIENTIFIC ARTICLE

Data do recebimento: $27 / 06 / 2017$

Data da aprovação final: 05/12/2017

\title{
Holistic Listening
}

\author{
A Escuta Holística
}

\section{Paul Rudy \\ University of Missouri-Kansas City \\ rudyp@umkc.edu}

\begin{abstract}
There are so many ways to listen to music and sound art. Western scholarship has focused on sound as symbol and language, and recent research into neurosciences, perception and cognition brings in a rich new aspect exploring exactly how our aural mechanism w orks and the how the brain interprets stimulus received by our ears. My own experience with sound has taught me that vibration acts upon my entire physiology and not just my ears. These experiences have returned me to listening with my whole body, dramatically affecting my physiology through sound. This article attempts to reconcile my training as a music listener guided largely by abstract thinking, with my understanding of listening as a whole body experiencer. The framework I posit here begins with listener triangulation strategies, and ends with a reincorporation of sound: a return to the body as a vibrational receiver in all of its aspects. The result is holistic listening with mind, body, emotions, and spirit, as sound becomes medicine with the power to heal.
\end{abstract}

Keywords: Electroacoustic Music; Musical Listening; Musical Cognition; Music Therapy

Resumo: Existem muitas maneiras de se ouvir música e artes sonoras. A tradição acadêmica ocidental se concentrou em estudar o som como símbolo e linguagem, e as pesquisas recentes em neurociências, percepção e cognição trouxeram um novo e rico aspecto explorando exatamente como os mecanismos auditivos funcionam e como o cérebrointerpreta os estímulos recebidos de nossos ouvidos. Minha própria experiência com o som ensinou-me que as vibrações agem sobre minha fisiologia inteira e não somente sobre meus ouvidos. Estas experiências me levaram a ouvir meu corpo todo, afetando dramaticamente minha fisiologia através do som. Este artigo tenta reconciliar meu treinamento como um músico ouvinte guiado amplamente pelo pensamento abstrato, com minha compreensão da escuta como uma experiência de todo o corpo. O contexto que eu proponho aqui começa com uma triangulação de estratégias de audição, e termina com uma reincorporação do som: um retorno do corpo como um receptor de vibrações em todos os seus aspectos. O resultado é uma escuta holística com mente, corpo, emoções e espírito, na medida em que o som se torna um remédio com poder de curar.

Palavras-chave: Música Eletroacústica; Percepção Musical; Cognição Musical; Musicoterapia

\section{MUSICA THEORICA}

Revista da Associação Brasileira de Teoria e Análise Musical Journal of the Brazilian Society for Music Theory and Analysis @ TeMA 2017 - ISSN 2525-5541 


\section{1 - Introduction}

The physical effect of sound has also a great influence upon the human body. The whole mechanism, the muscles, the blood circulation, the nerves, are all moved by the power of vibration. As there is a resonance for every sound, so the human body is a living resonator for sound. Although by one sound one can produce a resonance in all substances, such as brass and copper, yet there is no greater and more living resonator of sound than the human body. The effect of sound is upon each atom of the body, for each atom resounds; on all glands, on the circulation of blood and on the pulsation sound has its effect. (Inayat Kahn 1996, p.76)

As I drove through western Kansas in 2007, my fingertips vibrated in tempo with the ride cymbal of the music sounding quietly from my car stereo. The artist was Alison Krauss with Union Station, and the vibration was unmistakable. My fingertips were 'hearing' the music loud and clear as my skin responded in subtle sympathetic vibration even at a low volume level. The training I had received within the music academy had not prepared me for this experience. Intellectualization had relegated music and sound, nearly completely, to the realm of thought, with resignation that music could also trigger emotion. But emotions are messy and unquantifiable so even that was mostly avoided, especially in my composition and music theory training. My experience with Alison Krauss showed me how disconnected I was from a greater potential of sound, and that my graduate school indoctrination, of excessive writing, thinking, and talking about music is, as the saying goes, like dancing about architecture. Rarely did this lead me to new experiences beyond more thinking. Perhaps the dancing about architecture analogy is not entirely just here, however, because dancing about anything takes us out of our minds, and back into our bodies. The body is the instrument of dance, and time its stage, just like music and sound. In graduate school, over-intellectualizing about music became a way to validate it, regardless of how it sounded or more importantly: felt! Aspects of this training were rich and helpful, such as developing a good set of ears. But since that time, my body, emotions, and spirit have returned as valuable components of my listening equation. And it was Alison Krauss who plugged me in!

As my experience with music and sound deepens to include my whole body as a listening instrument, I have begun to explore what that means for my own creation and also broader reception of sound. Because sound is invisible, and yet acts upon any matter that it comes into contact, the subtleties of how we receive it go far beyond our intellectual ability to understand it. The mathematical objectivity and precision of frequency and tuning, for example, become imprecise, subjective and immeasurable, when interpreted by our brain. We can describe sound in very precise, objective, and measureable ways through experimentation, but once we hear it, our experience of it is unique, individual, and subjective. For this reason, I suggest that we need a more holistic model for 
listening: one that takes into account sound's interaction upon our physiology, emotions, spirit, and yes, our mind, as a whole.

This article describes theoretical foundations of holistic listening beyond my own personal practice of it. My point of departure is research in music, electroacoustics and recorded media, as I describe listener triangulation in sound contexts with source unseen, but which also applies to film, video game and multimedia genres as well. Understanding how we listen informs the rich potential of an integrated listening experience, where our whole self is engaged, and the full bandwidth of our amazing body is tuned in.

\title{
2 - Listener Triangulation
}

\author{
"Structure" is a much used (and abused) word in musical analysis and music \\ theory, and motor imagery could serve as a kind of 'deep structure' for musical \\ sound, offering a healthy antidote to unfortunate abstractions in musical \\ thought. This does of course pose profound challenges to our notions of \\ knowledge, as we would have to learn how to handle and represent knowledge of \\ our embodied 'feel' of movement" (Gødoy 2001).
}

Composing electroacoustic music with recorded material in the studio has become a process of 'composing as listener' for me. Like a sculptor, I listen to the material, and begin to chip away at it, uncovering all of its salient and often internal features. Composing as a listener means that the planning, structuring, developing and organizing of material is always subject to final approval by listening to the resultant sound in combination, rather than a pre-ordained or pre-planned template, form or organizational hierarchy. The material tells me where it wants to go, and what it wants to do, in a triangulated listening.

In 'listener triangulation', material, recognized or unrecognized, resonates with our own prior experience and/or memory, spontaneously stimulating feeling, and/or thinking about it. I use the term 'feeling' in the broadest sense here: to refer to intuition and emotion, as much as somatic sensation. This natural process that is both conscious and unconscious, takes into account the sound itself, and the source from whence it came. This happens automatically either instinctually or intentionally. Schaeffer's 'reduced listening', which asks us to ignore source recognition in recorded sound, promotes a detachment antithetical to the very evolutionary conditioning and uniqueness of our most direct, quickest and omnidirectional sense, adept at spatial location: hearing. To be sure, reduced listening leads to rich and deep aural experiences, but what of the other potential conveyed through the sound? Our brain labors in the background in many ways that we are not aware of, processing sound stimulation, searching for clues about our environment, and determining what needs our attention. 
'Listener triangulation' identifies these foundational layers of processing the potential for understanding sound in a musical or sonic art context.

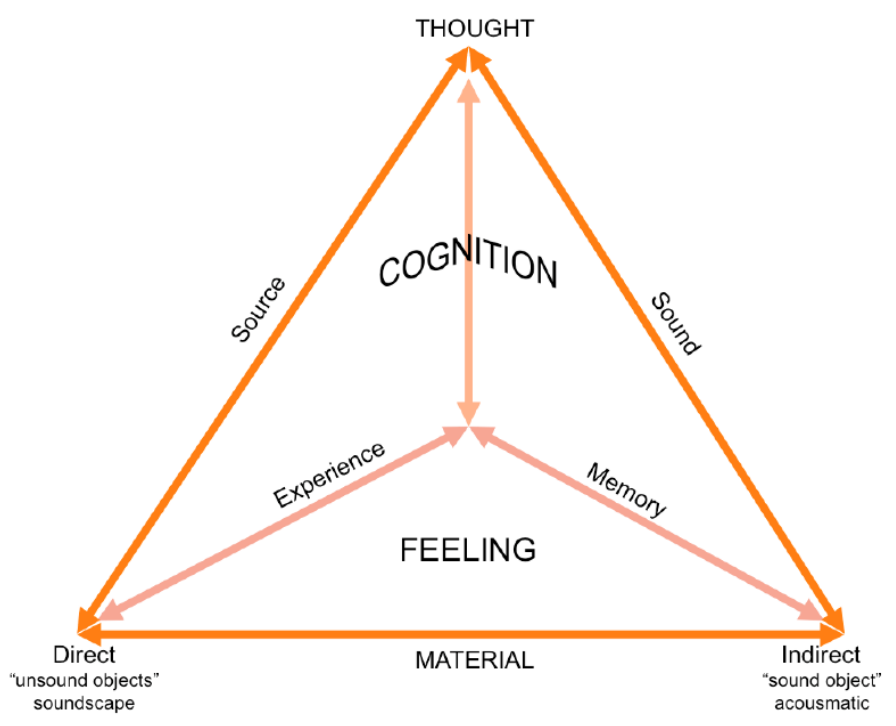

Figure 1: Listener triangulation

In the concert hall or bar, we see the ensemble before we hear it. Even before we go to the orchestra, string quartet, or jazz concert, we know what the source material will be, and what it sounds like, to varying degrees from general to highly specific. For example, if we plan to go hear jazz at the Village Vanguard, we already know that we will probably not hear bassoons. In the electroacoustic sound diffusion concert, or nightclub, with a DJ booth projecting recorded media over loudspeakers, we don't have this prior information. All listening experiences begin with material: either known before hand, or revealed in the moment, to varying degrees from general to highly specific.

Recorded material, with source unseen, communicates either directly or indirectly. Direct communication happens, as in soundscape music, when we recognize a place, an environment, a situation, or even a specific object making sound. It seeks to preserve source, place, and context, and indeed the composer intends to retain and convey some sense of the environment or subject at the heart of their creation. This type of sonic communication references something outside of the musical context itself, giving it a directness of information that extends beyond its own self-containment. In other cases, material communicates indirectly, through morphological language and structures in which the source may not be known. This type of material is built upon a self-referential internal logic created by the composer or sound artist. Sounds can communicate both directly and indirect, depending on the choice of the listener. Either way, material is where the listener HAS to begin, even more so in the electroacoustic context, where any sound source is possible and not constricted to the material of a 
limited set of lattice-sonics (Wishart 1996) or physical instruments. For this reason, new music is often hard for many to accept on its own, i.e. not in the context of a film, video game or other narrative scenario. The material simply is not familiar to them as that of the material of music, and similarly, the internal logic or structuring of that material may also be unfamiliar.

Material, and its behavior is what connects our experience of music to the real world, and vise-versa. If we recognize a sound, we have a direct connection with our prior experience with, or memory of it, and thus, its source. If we do not recognize it, we acclimate to this new material through our experience of sounds that behave similar to it. We update our lexicon, or reject them as 'not music,' but either way, we are invited (perhaps even forced!) to respond to this new material, whether consciously or not. Our prior memory and experience may come into play at any point if we allow it. When we recognize something, we access memories of it, either in prior musical contexts, or in outer-world experience. When we do not, we have the option to try to relate it to our learned (culturally or otherwise) experience with other music, or simply to its own internal logic and structure. This is a first step of sifting through material, and either feeling a direct connection with its source, or not. Rejecting the potential of prior knowledge and understanding of sound source dramatically limits the potential richness of the listening experience. Holistic listening encourages listening openly to things, rather than for things, and to freely navigate all of ones reactions and responses to that material no matter what the source or context.

\title{
2.1 - Cognitive and Feeling listening space
}

\author{
"...by almost all accounts the music of our distant ancestors was heavily \\ rhythmic. Rhythm stirs our bodies. Tonality and melody stir our brains. The \\ coming together of rhythm and melody bridges our cerebellum (the motor \\ control, primitive brain) and our cerebral cortex (the most evolved, most human \\ part of our brain)." (Levitin, 2006)
}

While the paths on the 'listener triangulation' diagram are linear and bidirectional, the actual experience traverses the surface areas in between the described bounds. In 'feeling listening space' (FLS), sound stimulates emotions, intuition, and gut feelings about what we encounter. FLS leads to the embodiment of sound either through direct somatic stimulation, or through emotions. 'Cognitive listening space' (CLS) stimulates thought and contemplation about what we are experiencing. Bodily empathy may be abridge between FLS and CLS. Godøy (2001), in discussing music and image, differentiates between 'signal' and 'schema' in audition and music cognition research. FLS is 'signal based', following a bottom-up approach, with the sound being experienced directly in body and emotions, often pre-cognitively. CLS is 
'schema based', and a top down approach, listening through thought, which can stimulate visual imagery. Intellectualization tends to take us out of our body, whereas conscious awareness of feelings can bring us back into our body.

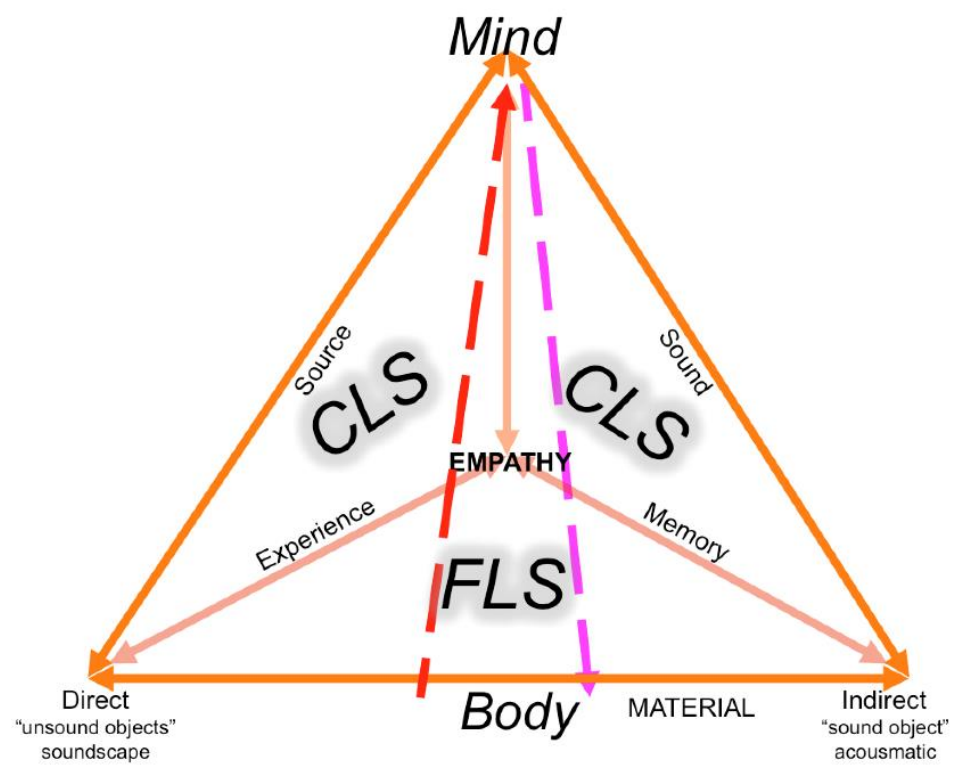

Figure 2: CLS/FLS and Body/Mind

I do not mean to imply that there is a strict order to how we navigate this web of potential relationships. For me personally, the richest sonic experience is one that creates a landscape of all of these potentials, so that I can navigate at will on the perceptual path of my own choosing, not one specifically prescribed by the creator. And as a composer, I seek to saturate the landscape with maximal potential for the listener to have a deeply personal and unique experience. This rich set of relationships and the terrain it creates, allows the listener to continually travel deeper and deeper both into the sonic art, AND into themselves, through their unique responses.

The list of sonic material, and sound behavior we might encounter in postelectroacoustic music, is as lengthy as the planet Herself. Rhythm is a special case, however, because it is processed by the oldest part of our brain, the cerebellum, and is also linked to emotion (Levitin 2006). Our body responds more unconsciously and directly to rhythm with a range of time division from periodic to gestural. Both have correlates rooted in our body: periodic rhythm through our heart beat and gestural rhythm experienced through our speech. Sped up to higher frequencies, periodic rhythm creates tone, and aperiodic, gestural rhythm shapes timbre ${ }^{1}$.

\footnotetext{
${ }^{1}$ A rhythm of 4 against 5 for example, when drastically sped up, will create the interval of a perfect $5^{\text {th }}$.
} 


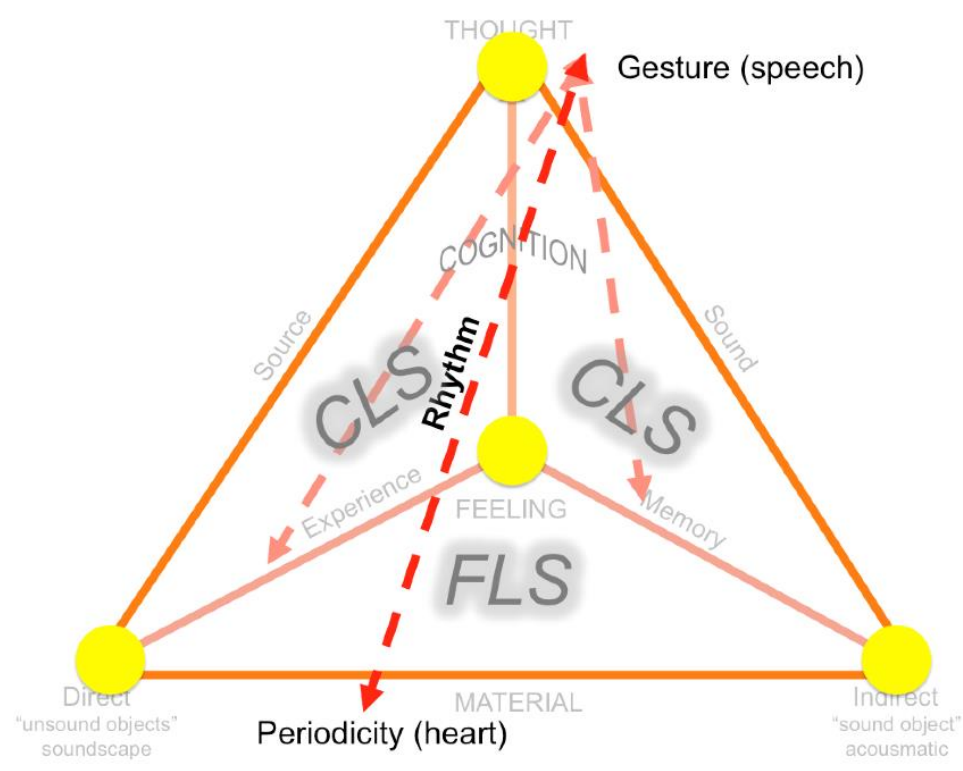

Figure 3: Listener Triangulation and Rhythm

Periodicity tends towards a bottom up flow (signal) through FLS, from our body to our mind, while speech tends towards the top-down flow (schema) in CLS, processed first through our conscious brain and often involving imagery. Certain types of speech, such as harsh words spoken in anger, can have a direct effect on the body because of the energy of delivery, triggering emotional responses that are felt directly. Foreign language that is not understood also stimulates bodily empathy because the use of voice is familiar to all of us even if we don't understand the words. Speech, then, in recorded media is a special case because it is normally processed through CLS, but can also overlap with FLS depending on the energy of delivery. Even if we do not understand their meaning, we listen differently to words.

Aperiodic division of time ranges from gesture, where attendance is towards the succession of discrete events, or horizontal listening; to textural, where attention is towards inner motion of a singular, usually longer event, through vertical listening. In gestural passages focus is successive and linear, and in textural passages, focus is on morphology of changing sound over time. (Smalley, 1986) These two trajectories correlate to the 'sudden change rule' (Smalley's 'gesture carried passages') in which "the auditory system will treat a sudden change of properties as the onset of a new event" and 'grouping by similarity rule' (Smalley's 'texture carried passages') in which “...similarities in the frequencies of pure tones, in spatial location, and in the spectral content and fundamental frequency of complex tones has been shown to affect grouping" (Bregman 1990). Periodic rhythm leans toward touch, expressed bodily through involuntarily tapping our foot, or moving our body to the beat for example. Gestural/textural division of time leans towards vision through transmodal visual imagery. Either way, varying degrees of bodily empathy is a listening 
potential because of our own experience of these divisions of time within our own bodies.

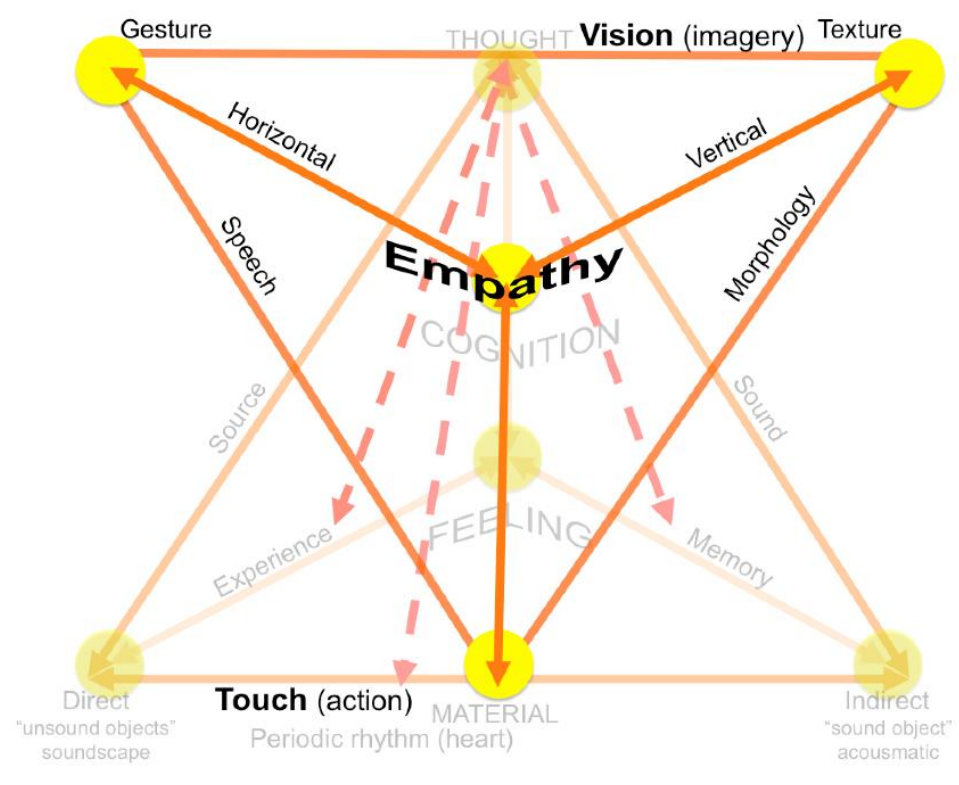

Figure 4: Touch-Vision Triangulation

As Pirsig (1974) writes in Zen and the Art of Motorcycle Maintenance: "Any intellectually conceived object is always in the past and therefore unreal. Reality is always the moment of vision before the intellectualization takes place." While this is a book of philosophical fiction, there is some evidence for his notion. In a sonic context, I would say that reality is always the moment of auralization before visual intellectualization takes place. In other words, how we first experience music and sonic art in our body and emotions is one thing, and our thinking about it become quite another. Reception is always in the ears of the listener because of our reflexive abilities to transliterate one sensual experience into another, and explore our bodily experience in thought.

The firm lines between what our body experiences as physical (signal) and what our mind imagines (schema) are breaking down under much new research. The relationship between the outer world and our inner state, it turns out, is much more fluid than our excessive thinking since Descartes has led us to believe. Godøy (2001) posits a triangular model of vision, action and audition, in discussing sound and image, where excitation and resonance are separable components in drawing meaning from physical dimensions of music. We distinguish between "what we do," which leads to motor images of how a sound is produced, and the "effects of what we do" which leads to material understanding of a source object. Either way, this speaks of a personal connection with the sounds we encounter, often determined by our prior knowledge of what makes it, or how other things like it sound. 
Our experience of the outside world can also occur entirely internally in our minds through mirror neurons.

In Braslau's perceptual symbol systems (PSS) framework, "The first tenet...is that knowledge (or internal representations) regarding perceptions, actions, and introspective states are represented in the same systems in which they are experienced. According to PSS, neurons, called 'conjunctive neurons,' receive different copies of the input signal from all of the senses (including vision, audition, olfaction, gestation, haptics, proprioception, and introspection) and store it for future cognitive use. Once these so-called conjunctive neurons are established, they can be activated by cognitive simulation in the absence of bottom-up input. 'Simulators' are distributed networks of conjunctive neurons that activate in response to a specific category. They are responsible for integrating the modality-specific information and forming a supramodal representation of a concept" (Oberman 2009).

In other words, once we have stored sensory input matrices, we have access to their cognitive use in the future without the direct physiological input! In my own experience, this can happen consciously, for example when daydreaming, or unconsciously through triggers activated by external stimulus. The notion of a supramodal representation approaches a universal language, where a fully formed concept is described mentally in totality. There are many who understand that animals communicate this way, but such a discussion is beyond the scope of this study. The notion of having complete concepts and understandings solely in our mind comes with a responsibility, however.

Our responses to environmental stimuli are indeed controlled by perceptions, but not all of our learned perceptions are accurate [especially if we have not personally experienced them!]...Yes, perception 'controls' biology, but as we've seen, these perceptions can be true or false. Therefore, we would be more accurate to refer to these controlling perceptions as beliefs. Beliefs control biology! (Lipton 2005).

Cole \& Jakimik showed that "...it is not only what we hear that tells us what we know; what we know tells us what we hear" (Howard and Ballas 1980). The study of imagery, neural mirroring, and work in epigenetics all seem to confirm that what goes on in our mind not only mirrors the outer world, with, or without stimulus, but may actually be creating it. It turns the notion that "seeing is believing" on its head. "Believing is seeing" may actually be a more accurate statement. Studies on 'change blindness' and 'inattentional blindness', in visual integration, show that we may completely miss detecting objects or changes in scenes if we are concentrating on a specific task. (Simon and Chabris 1999) This seems to confirm that what we see is not always an accurate reflection of what is 
happening. The same applies to sonic scenes. The external material world is not everything we think it is, and is shaped to a greater extent than ever known by our experience, our environment, and our beliefs about ourselves and the world around us, personally experienced or not!

It is self-reference that is the problem. The body cannot lie. Its bandwidth is too high for that. But the I can. In fact, the I can do nothing else. The I refers to itself as if it were the Me. But it is not. The I simulates being the $\mathrm{Me}$, having control of the Me. But the I is just a map of the Me. A map can lie. A terrain cannot. "I am a liar" is not a liar paradox. It is the truth about consciousness (Nørretranders 1998).

Our bodily experience of sound IS the experience, and our thoughts and languaging about it band-limits that experience into something completely different. Our experience cannot lie to us. Our thinking about the experience can. Holistic listening is a practice that can help us mediate and integrate these vastly differing potentials.

\title{
2.2 - Perceptual listening space
}

\begin{abstract}
As has become increasingly clear in the last couple of decades, there is probably alwaysan interaction and cooperation between a multitude of faculties and/or neural substrates in perception and cognition. What is most relevant...is the accumulation of research results supporting the idea of a quite strong integration of vision, action and audition... at the neurological level, ie. that integration of vision, action and audition is not only a phenomenon oflearning, but a matter of neurophysiological disposition as well (Gødoy 2001).
\end{abstract}

Truax (1994) describes a framework of context in sonic art listening: physical, social and psychological. Chion (1994) compressed Schaeffer's four modes of listening into three broad categories of content listening: causal, semantic and reduced. These are opposite points of departure: Truax from conext, and Chion from content, but share the framework of 'signal' to 'schema'. For example, the sound of walking on ice was completely foreign to my students from Mexico who had never experienced it. They had no causal or physical understanding through prior experience. That particular geographically localized content, by extension then, carried no social and cultural context for them either, like it did for my northern student who grew up walking on ice. The students who had never experienced the 'walking on ice' sound listened only in a reduced way, while my northern students had additional choices that included social and cultural implications surrounding activities related to the recognized source cause. These approaches are not mutually exclusive, but paths through them are dependent upon personal experience and understanding of source 
material. Physical/causal source-bonding in FLS listening, and psychological/reduced listening perspectives in CLS, create rich relationships and layers of potential meaning that rely heavily on our individual 'perceptual listening space' (PLS).

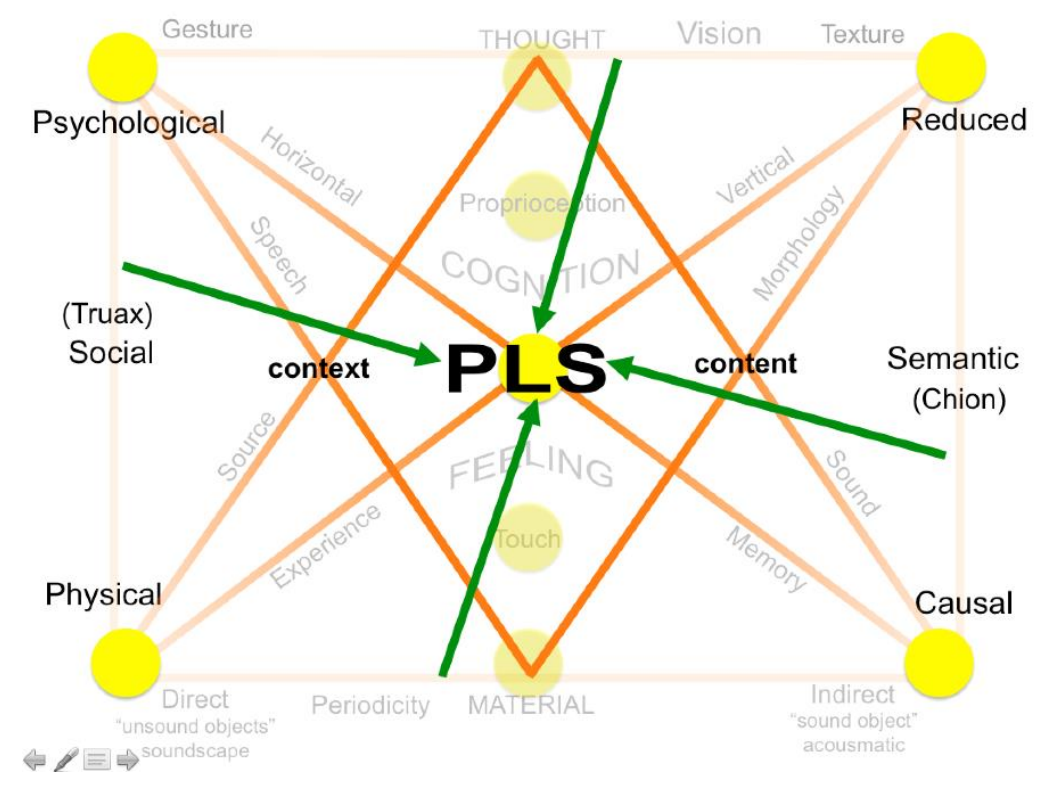

Figure 5: Perceptual Listening Space

PLS is where we interpret signs and symbols (semiotics) within a musical context as we delve deeper into sound experience. Aesthetic listening:

...resembles the way many listeners hear popular and some non-Western musics. In listening aesthetically as opposed to musically, we may choose to attend to development, or else we may pay only intermittent attention to sound while also attending to other sensory phenomena. Aesthetic listening also acknowledges that nonmusical sounds, the sounds of the outside world, can have aesthetic interest and that we can listen to them for more than simply their informational value (Demers 2010).

CLS is first and foremost, the realm of 'aesthetic listening': judgments and explanations correlating sound source with musical structure and development of material; continuously or intermittently, and mixed with other sensory phenomenon, culminating in discernment of what it all might mean. 'Musical listening' has the potential to guide us into both CLS and FLS. If we are listening to 'music as language' (i.e. its own internal logic, structuring and developing), we are approaching our experience through CLS. But, as we know, music can move us to dance or jump (at an unexpected loud sound for example), or feel emotions, when we are experiencing it in FLS. All of these potentials are content and context coupled in PLS. 
Context: what happens around and in proximity to a sound in a piece of sonic art; and content: the stuff of the sound itself, whether recognizable or not, are the bridges between signs and objects in both the Truax and Chion frameworks, and the bridge between FLS and CLS into PLS.

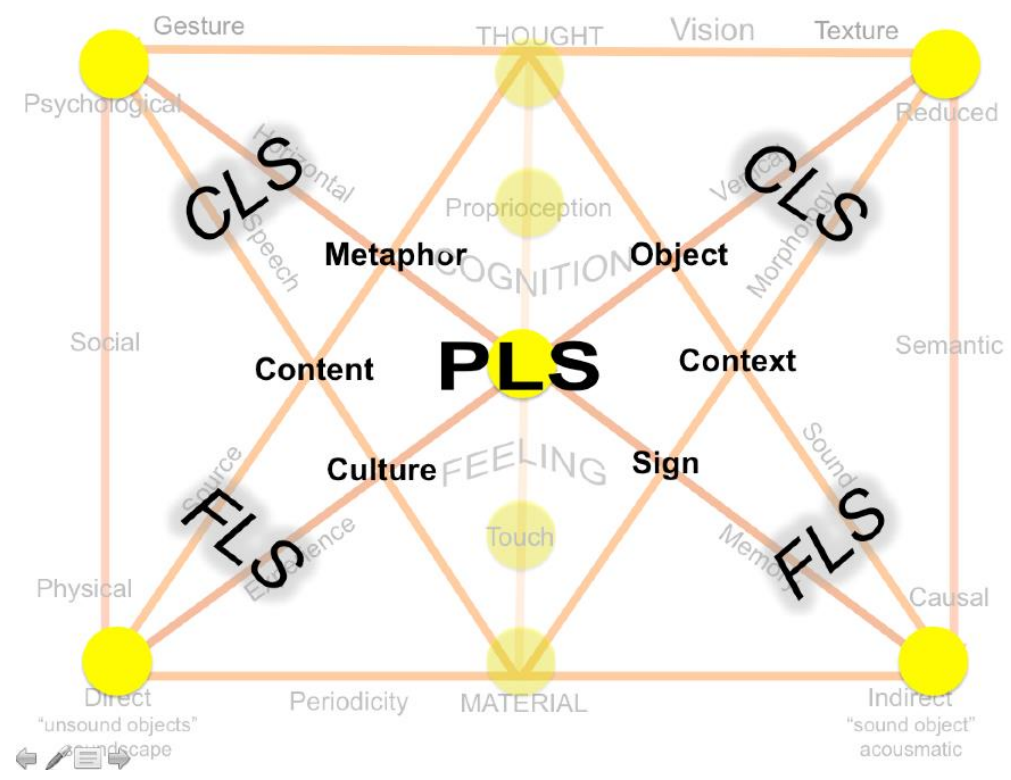

Figure 6: PLS and Semiotics

CLS tends to frame our experience in the past: tracking material and comparing what IS with what WAS: both in a piece of music or sonic art, and also in life's broader experiences. CLS can also put our expectations in the future with or without our awareness of doing so. Mandler showed that largely unconscious expectations are created for upcoming events and also inform future behaviors. Interrupting ongoing schema (audio steams for example) can stimulate a change in biology (Dowling \& Harwood 1986). So, while our body tends to experience sound in the present, the realms of our mind are past and future. Our mind wants to compare what is, with what was, as a way to predict what may be yet to come. And it is quite good at this prediction as long as sonic material has been encountered before. When we encounter new sounds, our whole body can react in FLS, but to further process the experience we must engage through CLS to increase our lexicon. Because of this, I have come to understand that sound experienced through FLS, with immediacy is a more accurate representation of my outer world (bottom up), while vision, because of the huge bandwidth it occupies in our cognitive mechanisms (Nørretranders 1998), is more a projection of the outer world, interpreted, or even created, through my individual personal will (top down). FLS tends toward unconscious awareness and body/emotion internal experience of sound, while CLS tends toward external projections. PLS 
oscillates between the two, seeking an understanding of how past, present and future interact through imagination.

Sonic art often maximizes these uncertainties by creating scenarios that can simultaneously be both lucid and ambiguous in PLS, prompting the listener to search deeper for understanding. We first try to resolve sonic ambiguities at the realm of physical experience, for example: "how does this scenario match my experience of the outer world?" If that doesn't work, we go deeper into the emotional or psychological interior of the sonic context. If that does not resolve the ambiguity, we turn to symbols and try to decode the meaning they convey through representing something else. For example, the Sanctus in Michel Chion's Requiem sets the text "Holy" in a way quite incongruent with how we have experienced this text in other requiem settings. We must look deeper to decipher what we think the setting is trying to represent (Jacobs and Rudy 2006). Nørretranders (1996) describes symbols and how they help “...us remember masses of information, even though we can keep only seven things in our minds at once. Symbols are the Trojan horses by which we smuggle bits into our consciousness". Listener triangulation and segregation of complex audio streams is determined in individual ways by how we choose (or not!) to navigate PLS, and space is a key element to that segmentation process. Where we place ourselves emotionally and psychologically (culturally and referentially) in relationship to material, development, physical placement in the sonic image, and location in time relative to other elements, determines how we segregate streams and group items together.

\section{3 - Dimension, Space and Time}

Our brain has an amazing ability to decipher and use subtle spectral variation to inform spatial awareness. Dimension (size, mass, density and even shape) is encoded into the sound itself. We do not need to see a door slam to know instinctively how much relative energy went into its slamming, just like we can feel the energy of someone shouting angrily even if we don't see the delivery or understand the words. We also decipher certain aspects of a recorded sound's material characteristics (hard-core, versus soft-core construction of the door for example), and even characteristics of the size and makeup of the room or space the event happened in.

Denis Smalley (2007) describes space-form as "... a way of integrating the multiple facets of the acousmatic image. A space-form approach is different from other methodologies in that it places time at the service of space". Smalley describes the notion of holistic space, made up of spaces within spaces, but

primarily delineated by morphology groups or types, and location within the stereo image. By delving deeper (differentiating groups, types, locations, 
distances, etc.) in each listening pass through space-form, he suggests "I can collapse the whole experience into a present moment, and that is largely how it rests in my memory". Despite the paradox of collapsing a whole experience (by definition over time) "into the present moment," stored in memory, which is the placeholder for the past, his concept draws to the forefront the notion that sound can simultaneously occupy us, through FLS present moment bodily experience and empathy, just as we can occupy the sound through CLS, past and future intellectual understanding/projections within it. Time begins to warp towards a convergence of memory (past), and expectation (future), in the present moment, perhaps conceptually similar to the way quantum physics describes the folding of time and space!

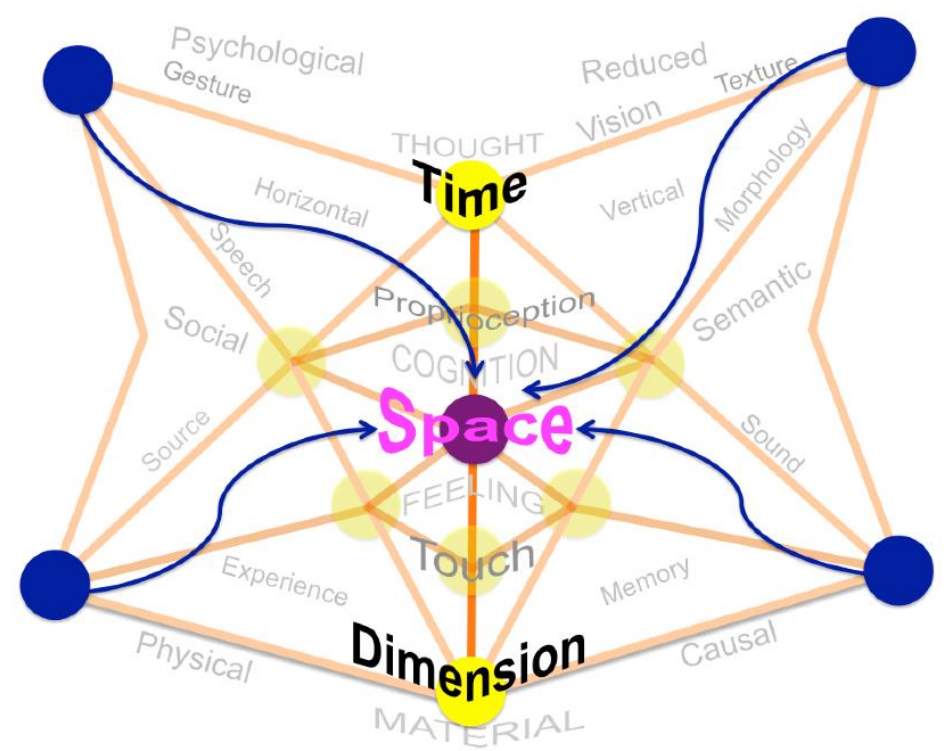

Figure 7: Space-Time-Dimension Fold

Key to Smalley's discussion of space-form is the notion of 'acoustmatic listening', which can be applied to any listening context, not just acousmatic music. Any time we listen, source-bonded sounds spill over and activate other senses. "Transmodal linking occurs automatically when the sonic materials seem to evoke what we imagine to be the experience of the world outside the music, and in acousmatic listening (not just acousmatic music) transmodal responses occur even though these senses are not directly activated in order only to listen." Our body, then, is key to holistic listening, as "sense experiences are also rooted in the physical and spatial entity of the human body, which is always at the focal centre of perception - as utterer, initiator and gestural agent, peripatetic participant, observer and auditor." (Smalley 2007) Research showing that music lights up our entire brain seems to confirm that we are already holistically engaged when listening to music (Levitin 2006), whether we are aware of it or not. Holistic listening is the practice of becoming aware of this lighting up from 
sound in all of its riches.

\section{4 - Perceptual Theory of Relativity}

Listener triangulation and our reception of sound, then, can be summed up in what I term the perceptual theory of relativity (with respectful apologies to Mr. Einstein). Content and energy, combined with context and experience ( $\left.\mathrm{ce}^{2}\right)$ compared over time and thought $\left(t^{2}\right)$ results in meaning $(\mathrm{M})$.

$$
\mathbf{M}=\frac{\mathrm{ce}^{2}}{t^{2}}
$$

Figure 8: Perceptual Theory of Relativity

Content (sound/material) which carries signature energy, is heard in a context (within the piece itself, or venue, or stylistic genre such as film, radio, concert, etc), through the lens of our own experience (prior, current, and expected), and these are then reconciled through thought in time, whether conscious or subconscious. The resulting triangulation, and thus experience for the listener, is highly personal and individualized. Our personal listening disposition leads to unique listening experiences. This 'perceptual theory of relativity' summarizes the domains of CLS, FLS and PLS. It is important to keep in mind, however, that probing the meaning imparted by music and sound art, by definition, tends to remove us from our bodily experience of it. Contemplation and thought (past/future) are not incompatible with bodily resonance (present), but it does take practice to remain in bodily listening mode when the mind dominates the reception.

\section{Inner/Outer and SLS}

Important rhythms exist in the oscillations of blood pressure waves. In healthy individuals a complex resonance occurs between blood pressure waves, respiration, and rhythms of the autonomic nervous system. Because pressure wave patterns vary with the rhythmic activity of the heart, they represent yet another language through which the heart communicates with the rest of the body. At the receiving end of the arteries are all the body's glands and organs. In essence, all of our cells 'feel' the waves of pressure generated by the heart and are dependent on them in more than one way. At the most basic level, pressure waves force the blood cells through the capillaries and provide oxygen and nutrients to all our cells. In addition, these waves expand the arteries, causing them to generate a relatively large electrical voltage. The waves also apply pressure to the cells in a rhythmic fashion, causing some of the proteins contained therein to generate an electrical current in response to the 'squeeze' (Childre and How ard 1999).

\section{MUSICA THEORICA}


In spectral analysis of two of my crystal singing bowls, played together, a third tone in the octave register below both is produce. The 11" bowls sounds at approximately D4 $(304 \mathrm{~Hz})$ and the 8 " bowl produces a tone near F\#4 $(382.5 \mathrm{~Hz})$. Sounding together, they produce a tone of E2 $(82 \mathrm{~Hz})$, which is not present in the spectral analysis, but which I hear very clearly. Difference tones such as this are not uncommon, although usually associated with harmonic, not inharmonic spectra. Our mind does many interesting calculations each and every time we encounter something, and often creates illusions, or phantoms of things not actually present. Diana Deutsch's experiments in sonic illusions present examples of how our psychoacoustic perception of something can be quite different from what is actually happening in the physical signal ${ }^{2}$.

The bulk of Western scholarship on music, listening and meaning, has been carried out in the framework of CLS and PLS through discussing how our inner understanding and reception of music and sound might represent or relate to the outer world. The inclusion of electroacoustic techniques into Western musics prompted a new domain in this conversation through cognitive and neurosciences. FLS in combination with PLS moves us deeper into understanding how our body and mind actually receive and interpret stimulus. Our conscious brain, however, is limited and slow at processing the full bandwidth of information streaming through our senses (Norretranders 1998), but our subconscious is aware of all of the data being received. 'Subconscious listening space' (SLS) is a cross-spatial collaboration between FLS, CLS, and PLS and integrates outer physical stimulus with inner collation of that stimulus fusing mind and bodily experience of sound.

The HeartMath Institute studies heart intelligence and has discovered that there are as many nerve endings in the heart, as in the subcortical sections of the brain. The 'brain in the heart' communicates with the brain in the head and processes information in a less linear, more intuitive way. Our heart intelligence is open to new possibilities, compared to the brain, which operates more linearly and seeks to corroborate all it encounters with what is already known. "The heart isn't only open to new possibilities, it actively scans for them, ever seeking new, intuitive understanding. Ultimately, the head 'knows' but the heart 'understands.' The heart operates in a more refined range of informationprocessing capability...it has a strong influence over how our brain functions" (Childre and Howard 1999). Dialog with our subconscious is called intuition, and our heart is the master of its intelligence in reconciling our inner world with outer stimulus!

2 Please see http://www.philomel.com/musical_illusions/for examples of these. Accessed 11/18/17 at 9:37 AM, UTC-6. 


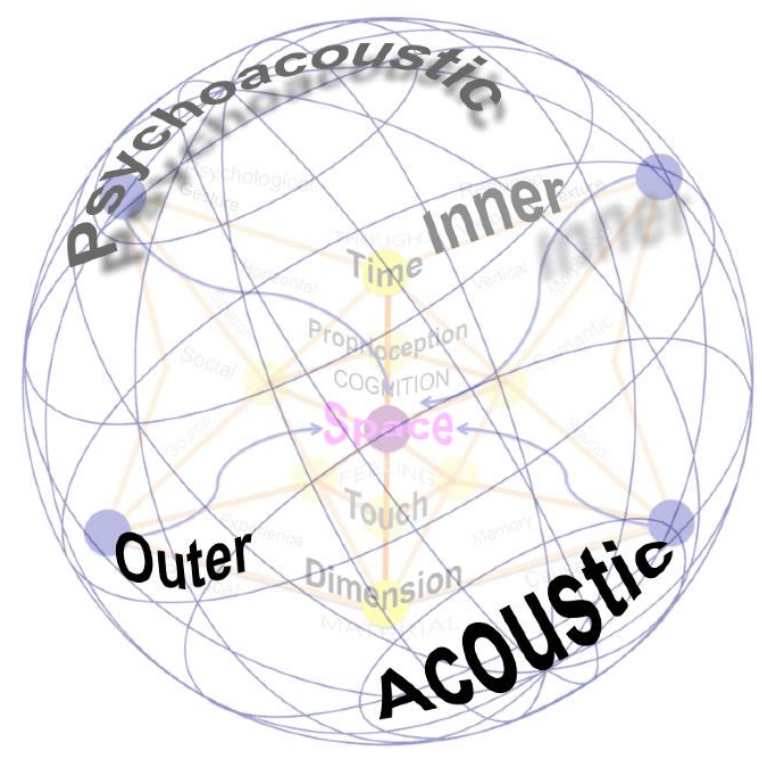

Figure 9: Inner/Outer

Meditation has long been used to quiet the conscious mind, in order to become aware of the full bandwidth of our subconscious experience, and many avenues are being explored to deliberately exploit awareness of this full bandwidth. In SLS, we acknowledge that sound vibration is acting upon our physiology regardless of whether we are aware of it or not. Inattentional blindness research shows that what we are not attending to visually, we often miss. The same can be true in sound: when we are consciously attending to a melody, for example, we may not notice that another instrument has joined in the accompaniment. Heart intelligence is aware of everything, and I believe has access to the full bandwidth of data the body encounters, and can intuitively guide us through the most challenging listening experiences.

Sound vibration is acting upon us constantly. Our reception of it is not dependent upon our awareness of receiving it because it vibrates our body physiologically. By welcoming our intuitive responses to stimulus, we can experience a greater, more profound depth of sound upon our entire physiology. Holistic sound practice is first and foremost about consolidating all our experiences of the sound, and the feelings it stimulates, to literally put the sound back into the bodies. In dualistic thought, the mind and body split became divisive, almost antithetical to each other. Through SLS, we begin to heal this divide between our mind and body and integrate and harmonize outer stimulus with our response to it. 


\section{4 - Holistic Listening Space (HLS)}

Mendelsohn said music is a much more precise language than words. Music speaks directly to the heart, through the molecules and it's irresistible (Zander 2017).

Sound awareness develops in the womb by 19 weeks gestation ${ }^{3}$ and is the last sense to close before we die $^{4}$. Because sound travels eight times faster in water than air, we "hear" vibrations directly through skin and bone conduction mediated through our amniotic fluid in the womb. This type of hearing does not end when we are born into the air, however. The WetSounds Underwater Concert Series $^{5}$ projects music under water in swimming pools through waterproof speakers. My music was selected during the project's first year in 2008, and hearing it in a swimming pool in Bath, England, was a life-changing experience. While in the pool, I conducted a simple experiment by submerging the back of my head but keeping my ears above water. In this position, with my ears open to the air, my brain's default was towards attending to the air conducted sound. But when I plugged my ears with my hands, my brain began listening again with whole body through bone and skin conduction. The perceived space and locality of the music with my ears closed, and with my whole body engaged as a sonic transducer, was omniphonic, rather than stereophonic as in air-borne sound.

Listening underwater, with my whole body transducer, I experienced the sound magically appearing directly in my mind ${ }^{6}$. I use the word appearing because it spontaneously stimulated my visual cortex. It felt like being back in the womb and I could see the sounds and their sources in my minds eye. In graduate school, I composed a dance work for non-traditional performers, one of which was deaf. When previewing the music with the dancers, the deaf performer held his hand over the speaker while the rest of us listened with our ears. Not only could the deaf performer tell me when the music changed, but $\mathrm{HOW}$ it changed in character in some detail. These experiences taught me that our bodies are complex listening instruments, and our lifetimes are literally framed by the sensory experience of sound vibrations interacting directly through that instrument. Because sound requires matter to propagate, our Earthly environment is, by definition sonic immersion! But because our brains automatically prioritize listening through air with our ears, it requires practice to hear vibrations with the rest of our body.

\footnotetext{
${ }^{3}$ http://www.ncbi.nlm.nih.gov/pmc/articles/PMC1061088/

${ }^{4}$ Hospice.org: Preparing for Approaching Death,

https://ww w.hospicenet.org/html/preparing_for.html 11/21/14:6:30 PM, UTC-6

${ }^{5} \mathrm{http}: / / \mathrm{www} \cdot \mathrm{w}$ etsounds.co.uk

${ }^{6}$ A related application is the Cymascope, which allows us to see the vibrations of sound visually through the medium of water. See http://cymascope.com
} 
And this brings us full circle back to FLS, but with an expanded view of tuning in to how our body is receiving sound through all of our physiology. Because our physiology is made up with a large percentage of water, our body through all of our molecules is constantly being stimulated by sound! HLS leads to many sound healing practices, as music becomes something much deeper and more profound than mere entertainment.

\subsection{Methods Incorporating Holistic Listening Space}

A short list of sound healing techniques include:

- Brainwave entrainment

- Binaural beats (LFO)

- Toning

- Acutonics (acupuncture with tuning forks)

- Shamanic drum journeying

- Singing bowls (metal and crystal)

- Gong and sound baths

Toning is one of the most powerful of these modalities that I have experienced, because it involves my own voice, perfectly fitted to my own physiology. It is one of the most effective self-healing tools available, and can be powerful in practicing HLS. And it is a practice available to all of us without instruction. Simply close your mouth, place the tongue on the roof of your mouth and hum while scanning your body. With practice you will hear parts of your physiology vibrating with different tones and vowel configurations. You can literally sing to any place in your body this way.

In shamanic drum journeys, other participants often share wild rides, based mostly on mental imagery, of going on a journey through real and fantastical places beyond what we know of in this physical plane. These types of experiences occur primarily in CLS/PLS, as they are described through mental imagery. My own experience has been quite different. I often experience feeling changes in my physiology, which I can best describe as shape-shifting: my hand becomes a talon, or my torso a tree trunk in the ground. Regardless of how we choose to label, or understand these experiences, my point is to differentia te between an experience that is perceived and understood only in the mind, from one that is felt and experienced directly by my body. I was pressed once, by another participant to find the symbol in the experience of my hand changing into a talon. But to me, the actually sensation of the physical experience carried far more significance than anything it could possibly signify. Even in spiritual circles, there is a tendency to prioritize metaphor in CLS, over the actual experience of feeling it profoundly in the body in FLS. 
To be sure, I can listen to the drum morphologically, rhythmically, and tonally. But when I go beyond all of these intellectual ways of listening, my body opens up to new sensations, and new experiences. I believe proprioception is key to these experiences, because it is the sense that combines inner experience with outer location, placement and understanding. Whether I actually shape-shift or not, is a matter of subjective perspective, and whether one believes that is possible or not. My point is not whether I actually shape shift or not, but that HLS enables new sound awareness that stimulates my whole body, mind, and spirit to light up! Synesthesia expands to include bodily experience and the feeling of bodily change, and this type of listening can connect not only our present life time of experience and knowledge directly to our body, but also recollections of past lifetimes and other physiologies as well.

\title{
5 - Conclusion: Beyond Listening
}

\begin{abstract}
Music...the popular medium that predates the written word shows promise but nonetheless "leaves the listener wanting more." The Onion, Pitchfork Gives Music a $6.8^{7}$
\end{abstract}

We tune instruments. Holistic listening is about tuning ourselves. I have a Crystal Tones Alchemy singing bowl that when I first played, did something very odd. When I sang perfectly in tune with it, so there was no beating, and then stopped singing, while continuing to bow the bowl, the note of the bowl mysteriously sounded a half step higher. My perception of my tone, in relation to the bowl, was out of tune! It took practice, but I eventually was able to tune my perception to match the actual acoustics. Cognitive and perceptual tuning is a field of great potential in understanding how we listen, and has huge implications for how we understand ourselves, communicate with others, make decisions, and move through life.

The goal of nearly every spiritual practice I have engaged in is to become present, and in the moment. Holistic listening asks just that of us: to be in the moment, tuned in with all our senses, 'listening' to sound and music with all of our faculties: our body, mind, and emotions, and without expectation. It asks us to be vulnerable to the vibration of sound and not just keep it at a distance by intellectualizing about it. I have discussed foundations of holistic listening with body, emotions, and mind, but so far have avoided the word 'spirit'. Spirit is an ephemeral way to discuss 'that which is unseen', and perhaps even indescribable, yet of which we are aware nonetheless. Our energy field or energy body is comprised of multiple layers: astral, emotional, mental, spiritual, and others, that project increasingly outward from a half-inch to many feet beyond our physical

$7 \mathrm{http}: / / \mathrm{w}$ w w .theonion.com/article/pitchfork-gives-music-68-2278, 9/10/07 12:01am 
body. Sound is literally interacting with us even before it reaches our body, and when it does, it penetrates us down to a molecular level. This realm is beyond the scope of the present article, but is the frontier of the holistic listening for the purposes of healing. When we learn to tune our energy field in synchronicity with our physiology at a cellular level, we have the power to self-heal. Holistic listening is one of the most powerful tools to accomplish that.

Sound stimulates the body into action, and the mind through memory and personal experience. Through listener triangulation, a song prompts time travel through memories by reminding of us of prior experiences or emotions through signs and symbols. A ringing bell alarms or brings people together as a signal. Cymatics shows us that a tone vibrating a steel plate can organize sand into geometric shapes ${ }^{8}$. A voice can shatter glass with enough focus and amplitude 9 , and recent experiments show sound levitating and moving objects on a smallscale version of the "tractor beam" invented long ago in science fiction ${ }^{10}$. Sound is an organizing or focusing principle through constructive resonance, or a diffusing energy through destructive resonance, that acts upon whatever it contacts. Holistic listening brings these resonances into our conscious awareness through practice.

Many scientific fields have gone down the rabbit hole of exploring remote, nonlocal, nonphysical, interactions of subtle energy, just as my own experiences with sound have taken me there. Sound is a powerful expression of oscillating energy at the lowest end of the frequency spectrum. In physics, energy is defined as a property that can be transferred from one object to another, cannot be created nor destroyed, and also is the ability of a system to do work. Because energy can only be transferred and not destroyed or created, all music, the vibrations of sound are resonances of original source energy, passed, shaped, filtered, changed, amplified, attenuated and resonated by whomever they come into contact! Holistic listening is an invitation to let go of probability space, and surrender to possibility space, where anything, past, present, and future is available to our experience in creating our own holographic Universe. And sound and music are key building blocks of that Universe, and we are its architects.

\footnotetext{
8 A term coined by Hans Jenny who discovered that sound organizes matter into patterns.

${ }^{9} \mathrm{http}: / / \mathrm{w}$ w w .scientificamerican.com/article/fact-or-fiction-opera-singer-can-shatter-glass/

10 http://w w w .livescience.com/52598-sonic-tractor-beam-moves-objects.html
} 


\section{References}

1. Bregman, Albert S. 1990. Auditory Scene Analysis: The Perceptual Organization of Sound. Cambridge, Mass.: The MIT Press.

2. Childre, Doc; Howard, Martin. 1999. The HeartMath Solution. New York: Harper One.

3. Chion, Michel. 1994. Audio Vision: Sound on Screen. New York: Columbia University Press.

4. Demers, Joanna. 2010. Listening through the Noise: The Aesthetics of Experimental Electronic Music. Oxford: Oxford University Press.

5. Dowling, W. Jay; Harwood, Dane L. 1986. Music Cognition. Orlando: Academic Press.

6. Godøy, Rolf Inge. 2001. Imagined Action, Excitation and Resonance. In: Musical Imagery, pp. 237-250. R. I. Godøy and H. Jørgensen (eds.). Lisse: Swets and Zeitlinger.

7. Howard, J.; Ballas, J. 1980. Syntactic and Semantic Factors in the Classification of Nonspeech Transient Patterns. Perception E Psychoacoustics 28:5, p. 431-439.

8. Inayat Khan, Hazarat. 1996. The Mysticims of Sound and Music, revised edition. Boston/London: Shambhala.

9. Jacobs, Sarah L.; Rudy, Paul. 2006. Noise, Dissonance and the TwentiethCentury Spiritual Crisis: Synchresis in Chion's Requiem. New Orleans: Proceedings from the International Computer Music Conference, p. 229-236.

10. Levitin, Daniel. 2006. This is Your Brain on Music: The Science of a Human Obsession. London: Plume.

11. Lipton, Bruce. 2005. The Biology of Belief: Unleashing the Power of Consciousness, Matter $\mathcal{E}$ Miracles. Carlsbad, CA: Hay House.

12. Nørretranders, Tor. 1998. The User Illusion: Cutting Consciousness Down to Size. Jonathan Sydenham (trad.). New York: Penguin Books.

13. Oberman, Lindsay M.; Ramachandran, V.S. 2009. Reflections on the Mirror Neuron System: Their Evolutionary Functions Beyond Motor Representation. In: 
Mirror Neuron Systems: The Role of Mirroring Processes in Social Cognition, p. 39-62. Jaime A. Pineda (ed.). New York: Humana.

14. Pirsig, Robert M. 1974. Zen and the Art of Motorcycle Maintenance. London: Vintage.

15. Smalley, Denis. 2007. Space-form and the acousmatic image. Organised Sound 12(1), p. 35-58. United Kingdom: Cambridge University Press.

16. Smalley, Denis. 1986. Spectro-Morphology and Structuring Processes. In: The Language of Electroacoustic Music, p. 17-40. Simon Emmerson (ed.). New York: Harwood.

17. Truax, Barry. 1994. Complexity Forum: The Inner and Outer Complexity of Music. Perspectives of New Music, 31:1 p. 176-193.

18. Wishart, Trevor. 1996 (1983, 1 ${ }^{\text {st }}$ Ed.). On Sonic Art. Amsterdam: Harwood.

19. Zander, Benjamin. 2017. Subject interviewed on TED Radio Hour [Audio podcast]: How Art Changes Us, Guy Raz [producer]. Retrieved from: http://itunes.apple.com 